\title{
Empirical Monetary Valuation of a Quality-Adjusted Life-Year in the Kingdom of Saudi Arabia: A Willingness-to-Pay Analysis
}

\author{
Shouki Bazarbashi ${ }^{1}$ - Edward B. De Vol $^{2} \cdot$ Fatma Maraiki $^{3} \cdot$ Ahmed Al-Jedai $^{3} \cdot$ Afshan A. Ali $^{4} \cdot$ Ali M. Alhammad $^{5}$. \\ Ibrahim A. Aljuffali ${ }^{6} \cdot$ Michael Iskedjian $^{7,8}$
}

Published online: 14 April 2020

(c) The Author(s) 2020

\begin{abstract}
Background No willingness-to-pay (WTP) per quality-adjusted life-year (QALY) value exists for the Kingdom of Saudi Arabia (KSA).

Objective The primary objective of this study was to determine the WTP for a QALY in the KSA.

Methods Adult citizens of the KSA, patients with cancer, or members of the general public (MGP) were recruited to participate in a time trade-off survey to elicit health utilities. Cancer was chosen as the disease of interest for patients and the MGP, with a scenario describing stage 3 colorectal cancer, because it is a disease condition that impacts on both quality of life and survival time. In a second step, respondents were asked about their WTP to move from the estimated health state to a state of perfect health for 1 year (QALY). Finally, that amount was processed to generate the WTP for a full QALY. The second step was repeated with a 5-year horizon. Sensitivity analyses were performed without outliers.

Results From 400 participants, data from 378 subjects were obtained and usable: 177 patients, 201 MGP; 278 male, 100 female subjects; 231 aged 26-65 years. Demographic distribution varied widely between the two subgroups for age, education level, and employment status, but with less variation in sex and income. Elicited health utilities were $0.413(0.472$ after adjustment) for the overall group, $0.316(0.416)$ for patients, and $0.499(0.508)$ for MGP. Overall WTP for a QALY was \$US25,600 (adjusted \$US32,000) for the 1-year horizon and \$US19,200 (adjusted \$US22,720) for the 5-year horizon. Conclusion This was the first empirical attempt to estimate the WTP per QALY for the KSA. Results are comparable to those in some other countries and to gross domestic product figures for the KSA. Further research in a country-wide sample is warranted.
\end{abstract}

\section{Introduction}

One key piece of data in the process of medication reimbursement is a threshold that reimbursement decision makers, mainly health authorities, call the willingness to pay

Electronic supplementary material The online version of this article (https://doi.org/10.1007/s41669-020-00211-0) contains supplementary material, which is available to authorized users.

Michael Iskedjian

miskedjian@pharmideas.com

1 Section of Medical Oncology, King Faisal Specialist Hospital and Research Centre, Riyadh, Kingdom of Saudi Arabia

2 Biostatistics, Epidemiology, and Scientific Computing, King Faisal Specialist Hospital and Research Centre, Riyadh, Kingdom of Saudi Arabia

3 Department of Pharmacy, King Faisal Specialist Hospital and Research Centre, Riyadh, Kingdom of Saudi Arabia

4 Department of Pediatric Hematology/Oncology, King Faisal Specialist Hospital and Research Centre, Riyadh, Kingdom of Saudi Arabia

5 Drug Policy and Economics Center, National Guard Health Affairs, King Abdulaziz Medical City, Riyadh, Kingdom of Saudi Arabia

6 Department of Pharmaceutics, King Saud University, Riyadh, Kingdom of Saudi Arabia

7 PharmIdeas USA Inc., 1967 Wehrle Drive, Unit 9, Williamsville, NY 14221, USA

8 Associate Clinician, Faculty of Pharmacy, University of Montreal, Montreal, Canada 


\section{Key Points for Decision Makers}

Median willingness to pay for a quality-adjusted lifeyear (QALY) was estimated at \$US19,200-32,000 in the Kingdom of Saudi Arabia (KSA).

This range is in line with the per capita gross domestic product of approximately $\$ \mathrm{US} 20,000$ in the KSA.

Decision makers can use this range as a threshold for the cost per incremental QALY in decision making around reimbursement for a drug or healthcare intervention.

(WTP) for a quality-adjusted life-year (QALY). In more simple terms, this is the maximum that a plan or authorities would disburse to secure 1 additional year of life with perfect health and therefore reimburse medications or procedures that would yield incremental cost-effectiveness ratios (ICERs) lower than the WTP for a QALY.

Many Western countries that have some sort of formal medication reimbursement process, such as the UK or Canada, apply threshold values for cost effectiveness, below which a medication is considered cost effective or above which a medication is no longer considered attractive to authorities. Cameron et al. [1] identified 17 countries with a formal threshold; most have either an implicit or otherwise unclear threshold.

Some of those countries use thresholds varying from CAD20,000 per QALY in Canada for definitely attractive drugs [2], to $\$$ US50,000 in the USA for cost-effective drugs [3-5], or about $£ 20,000-36,000$ in the UK [6, 7], and $€ 50,000$ in Italy [8], Sweden [9], and the Netherlands [10]. One study evaluated Australian Pharmaceutical Benefits Advisory Committee outcomes for submissions from 2005 to 2009 ; approximately $50 \%$ of the positive recommendations accepted for listing had an ICER of $>$ AUD45,000, whereas $33 \%$ of the negative "against" recommendations had an ICER range of AUD45,000-75,000 per QALY gained [11].

Although the reported use of a threshold of \$US50,000 in North America emerged from a study of renal dialysis, it appears to have been adopted more because it is an easily applied round number [12]. In turn, Rudmik and Drummond [13] reported a convenient range of $\$ U S 50,000-100,000$ for the threshold in the absence of an official value, whereas King et al. [5] questioned the validity of a threshold of $\$$ US50,000. For the UK, Claxton et al. [14] reported new approaches to estimating the value of a QALY, as no empirical estimates had previously been available for the threshold applied by the UK National Institute for Health and Care Excellence.
In fact, very few countries have explicit or even implicit threshold values, and even fewer have the value empirically determined. No QALY threshold exists for the Kingdom of Saudi Arabia (KSA). Hence, the primary objective of this study was to empirically determine the monetary value of a QALY in the KSA.

\section{Methods}

The QALY is regularly used to assess the cost effectiveness of drugs, especially those used to treat diseases and illnesses with a high impact on quality of life, such as most types of cancer, or drugs that significantly affect patient quality of life, such as some chemotherapy protocols. This type of costeffectiveness analysis is often called cost-utility analysis. Utility, or health state utility, or simply health utility (HU) is the quantitative measure of quality of life in healthcare, with 1 QALY being equal to 1 year of life with a utility of 1 (or $100 \%$ ); 1 QALY is also equal to 2 years of life with a utility of 0.5 (or $50 \%$ ), or 4 years of life with a utility of 0.25 (or $25 \%$ ), etc., whereas utility scores may range from 0 to 1 (or $0-100 \%$ ).

Soares Santos et al. [15] identified three approaches for calculating thresholds for a QALY: the WTP method, the precedent method, and the opportunity cost method. Our study applied the WTP approach. The present study consisted of a two-part survey that determined the utility scores of participants and their WTP for a QALY. The online survey was conducted between April and December 2017, with help from three trained interviewers. Recruitment was done at the King Faisal Specialist Hospital and Research Center (KFSHRC), a tertiary institute. This study was approved by the ethics review board of KFSHRC, Riyadh, KSA. All study participants signed informed consent prior to starting the survey. Patients with cancer, their visiting relatives, and some KFSHRC personnel were recruited on site by the interviewers. Interviewers logged in on the survey site with a unique user code for each participant, read the questions to the participant, and entered the participant's answers.

\subsection{Subjects}

Participants in the study were citizens of the KSA, either patients with a solid tumor diagnosis from the KFSHRC or members of the general public (MGP) recruited at KFSHRC, including family members of patients, healthcare professionals, or members of the larger community. The minimum age for participation was 18 years; no maximum age was applied. Participants also had to understand the Arabic language and provide informed consent. Patients with hematological malignancies or lymphoma were excluded as the study was centered at the solid tumors unit of the hospital. 
Online calculators indicated we needed a sample of $\geq 385$ participants for the survey for a confidence level of $95 \%$ and a margin of error of $5 \%[16,17]$.

\subsection{Study Approach and Survey Tool}

Data collection was carried out in two steps: a time trade-off (TTO) survey followed by a WTP assessment. Elicitation of HU with the TTO method has been described elsewhere [18, 19], including an electronic version of the TTO [20]. The TTO component is summarized and the WTP component and the calculations to obtain the amount for a full QALY are described in detail.

The first step consisted of eliciting the HUs for patients in a given disease condition, i.e., cancer. This first step could be done through two approaches: (1) through direct survey of patients and measurement of their own health-related quality of life or (2) through the general public by presenting a scenario describing a certain cancer-related health state and asking them to rate the quality of life for the given health state. HUs were measured using the TTO technique. In the TTO, the respondent was presented with two choices: (1) to live for a given length of time with the current condition followed by "instant painless death" or (2) to live fewer years but in full health followed by "instant painless death." The duration of time in full health was adjusted using a "pingpong" game technique, until the participant was indifferent between the two options. The maximum number of years that could be traded as applied to the current health state was 10 years or 120 months. This measure allowed us to quantify the health-related quality of life and calculate the number of QALYs over a certain period of time. For example, if a participant was willing to give up 72 months (6 years), then we calculated that $72 / 120=0.6$ or $60 \%$ of the time was traded off, hence $100-60 \%=40 \%$ of the remaining time in perfect health indicated an $\mathrm{HU}$ of 0.4 .

The second step consisted of asking both patients and MGP how much they would pay out of pocket to reach perfect health. This step actually consisted of evaluating the subject's WTP for transitioning from a given health state to perfect health. For patients, it consisted of their own health state; for MGP, it was the health state described in the presented scenario. The WTP was determined using the bidding game technique, as applied in previous studies [21-23] again in a "ping-pong" fashion. Once we had a monetary value for transitioning to perfect health over a certain period of time, we calculated the monetary value of a QALY as estimated by the survey respondent, since we had previously calculated the number of QALYs over that same period for the same respondent.

The content, wording and formatting of the survey were evaluated and assessed for face validity by two members of the research team, an expert clinician (SB) and a researcher with expertise in this area of health economics (MI). Arabic translations were carried out at KFSHRC. MGP were presented with a health state describing a particular scenario that may be faced by a patient with stage 3 colon cancer, including all relevant clinical characteristics, standard treatment options, and their potential impact on a patient's quality of life.

\subsection{Determination of the Willingness to Pay Per Quality-Adjusted Life-Year}

Participants were asked for an amount they were willing to pay to move from their present state to 1 year of perfect health. This WTP was then applied to 1 QALY. The participants were first asked the monthly WTP in Saudi Arabia riyals (SAR; $\$$ US $1=$ SAR3.75) for a period of 1 year. After the 1-year bidding game was completed, participants were asked what amount they would pay monthly for 5 years, and a new bidding game was applied. Bidding games started randomly with one of the following amounts: SAR500, SAR1500, or SAR2500. These amounts were chosen to provide reasonably affordable starting figures for all participants, as a monthly salary of $<$ SAR3000 is considered among the lowest. A "ping-pong" sequence was applied with a maximum bid of SAR10,000 and a minimum of zero. If a participant answered yes, a new amount was proposed at the midpoint between the maximum and their starting amount. If the answer was no, a new amount was proposed as the midpoint between zero and their starting amount. The sequence continued with amounts proposed at midpoint between their last choice and either the minimum, the maximum, or the starting amount, varying with the last answer received. Minimum increments were SAR100. When the bidding game yielded a certain WTP amount after the "ping-pong" sequence with no further possibilities, participants were asked whether they were willing to pay that amount. If they said yes, it was considered their answer. If they said no, they were asked what amount they were willing to pay and asked to confirm it. Figure 1 represents a schematic illustration of the WTP component of the survey. Figure 2 presents a sample slide from the patient version of the WTP questionnaire. Finally, results were calculated and presented in \$US, with $\$$ US1 = SAR3.75 (year 2018 values).

In a first step, we calculated WTP $=x /(1-y)$, where $x$ was the amount proposed by the participant and y was the product of 1 year in the present health state multiplied by the HU for that health state. Accordingly, a WTP amount was determined for a full QALY. For example, a participant who offered \$US1000 monthly (\$US12,000 annually) to move to perfect health had a utility of 0.4 , so this WTP was calculated to be $\$$ US12,000/(1-0.4) $=\$$ US12,000/0.6 QALY or \$US20,000/1.0 QALY. The participant's WTP per full QALY was then determined to be $\$$ US20,000. 
Fig. 1 Algorithm of the bidding game

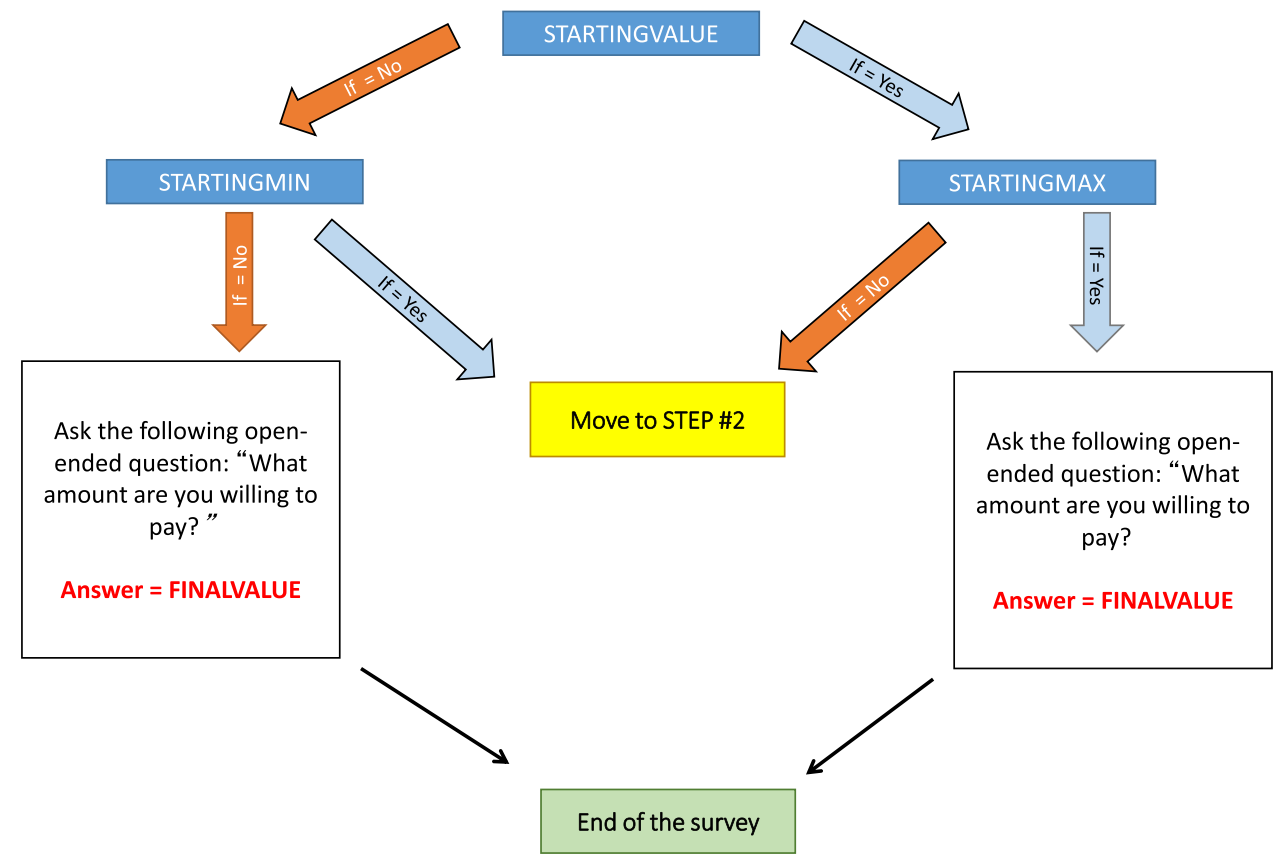

Valuation Component - Introduction
Thank you for completing the previous portion of the survey, we are almost done.
In this part of the survey, we will ask you three sets of questions:
1) We will ask you to try to imagine that you are in your present Health State and ask you how much you would be willing to pay to have
access to a pill guaranteeing you perfect health for one year.
2) Same situation as in \#1, you are in your present Health State but this time the pill guarantees you perfect health for five years
Fig. 2 Sample slide from the willingness-to-pay questionnaire (patient version)

\subsection{Analysis}

Demographic statistics were determined both for the overall sample and separately for both patients and MGP. We calculated means, medians, and percentile results for WTP per QALY. Although the WTP survey was conducted with amounts asked in SAR, results are presented in \$US, with \$US $1=$ SAR 3.75 (year 2018 values). The median was considered the most adequate result, as extreme outliers can skew results in health economics, whereas the median remains in the middle of the least and the most amount offered. WTP per QALY was determined for the two time horizons: 1 and 5 years. Analyses were carried out to compare results between subgroups defined by sociodemographic characteristics and to determine whether the difference was statistically significant in some of those comparisons. The statistical package used for analyses was SAS 9.4.

\subsection{Sensitivity Analyses}

A first series of sensitivity analyses were carried out on the results from the HU component. Adjusted results were calculated after eliminating outliers. Outliers for utility scores were considered as the bottom and top 5\% of the utility range, hence the adjusted dataset was limited to $0.05<$ utility $<0.95$. A second, more restrictive, set of analyses were performed, removing both the outliers on the utility results and outliers on the WTP amounts, hence eliminating outliers who fell outside of those with $0.05<$ utility $<0.95$ and $10 \%<\mathrm{WTP}<90 \%$, or the participant answers at the top or bottom $5 \%$ of the utility range and those at the top or bottom $10 \%$ of the WTP range. These sensitivity analyses were deemed important because, in health economics, especially with a bidding game with an open-ended ceiling, data can be skewed mostly toward the upper end. Hence, these 
sensitivity analyses were performed to adjust, to a certain extent, for that skewness.

Finally, we performed sensitivity analyses to adjust for actual demographic rates from the general population of the KSA [24]. This was done by multiplying age and sex subgroup results by corresponding epidemiologic figures based on the demographics from the general population statistics of the KSA.

\section{Results}

From 400 survey participants, data from 378 subjects (177 patients; 201 non-patients) were deemed usable for analysis. Data from the other 22 subjects could not be retrieved and were therefore unusable because of technical issues with data transmission to the central database. In total, 134 patients had stage III or IV cancer, with the five most common types being colon, rectal, renal, gastric, or prostate cancer. Table 1 provides the participant demographics for the overall sample and the two subgroups. Most participants were males (73.5\%), and the sample was almost equally divided between employed and unemployed. More than half (58.2\%) were aged 36-65 years, and less than one in ten $(9.5 \%)$ were aged $>65$ years. The subgroup aged 26-35 years had the most participants (22\%), closely followed by the subgroup aged 36-45 years (21.7\%). The subgroup of participants with a bachelor's degree was the largest (41.5\%), followed by those who did not complete secondary school (19.6\%). Half of the participants had a monthly income of more than SAR12,000 (\$US3200), and the largest subgroup (27.5\%) was those earning SAR6001-12,000 (\$US1600-3200).

Table 2 summarizes the HU scores determined in the first part of the survey, i.e., the TTO component. Mean utilities are presented for the overall group as well as separately for the patient and non-patient groups. After two-way adjustments, i.e., eliminating outliers from the utility scores and from the WTP results, the mean utility scores fluctuated round 0.5 , with the patient group reporting a lower mean than the non-patients: 0.42 and 0.51 , respectively.

Tables 3 and 4 present the WTP results for the 1-year and the 5-year horizons, respectively. For the 1-year time horizon, the median WTP per QALY was \$US25,600; after adjustments (without outliers), it was $\$$ US32,000. For the 5-year time horizon, the results were slightly lower, at \$US19,200 and 22,720 per QALY, respectively, before and after adjustments. After adjustment without outliers, we determined the means to be $\$$ US58,000 for the 1-year horizon and \$US38,600 for the 5-year horizon, figures that are much closer to the medians than the unadjusted means.

Figure 3 is a logarithmic representation of WTP per QALY by utility scores. It is interesting to note a somewhat positive association between WTP and utilities. In turn,
Fig. 4 illustrates the rather negative association between WTP and age, with WTP decreasing with increasing age.

In sensitivity analyses, where we adjusted for age and sex based on official statistical data for the KSA, after projecting WTP amounts from the age and sex subgroups into corresponding subgroups in the KSA, we obtained WTP per QALY median amounts of \$US31,909 for the 1-year horizon and \$US22,926 for the 5-year WTP results. These results are very close to the main results, adjusted after excluding outliers.

\section{Discussion}

This study is, to the best of our knowledge, the first to determine the WTP per QALY in the KSA. It provides threshold results that will be useful in determining whether a new drug or intervention is attractive by comparing expected ICERs with these threshold results, in terms of \$/QALY gained. Hence, if an economic analysis of a drug yielded an expected ICER of less than the WTP amount determined in our study, i.e., \$US25,600, or 32,000 after adjustments, for the 1-year time horizon, the reimbursement price of the drug may be deemed attractive. The WTP results are somewhat lower in the 5-year horizon analyses (\$US19,200-22,720).

This study does not provide definitive WTP per QALY thresholds, but it does present a first provisional set of thresholds that could guide future pharmacoeconomic studies, at least until more solid results are obtained in a larger and more representative sample. Nevertheless, when compared with the gross domestic product (GDP) in the KSA, which is approximately $\$$ US20,000 per capita, our results come rather close to the GDP figure within the 1-year horizon and narrowly overlap it within the 5-year horizon. Although we are comparing medians and a mean GDP, mean and median should be similar, if not identical, in a large setting such as a whole country. Obviously, to get such results, we used the median rather than the mean and had to eliminate the outliers, i.e., extreme values in both HU scores and WTP amounts. This approach is used in health economics to avoid very wide variations within a sample. In fact, in our sample, results went from zero to over \$US38 million. As it is difficult to obtain such a distribution in this type of analysis, we defined the outliers with what we considered acceptable limits: $\pm 5 \%$ for utilities and $\pm 10 \%$ for WTP. It should be noted that medians were lower than means, as reported in our previous WTP studies [21, 22]. The previous studies also found no starting point bias, as no statistically significant differences were reported between groups starting the bidding game with different amounts. We did not perform such an analysis in the present study because this was not one of the study objectives. This approach may be a limitation. Furthermore, the aim of the present study was 
Table 1 Demographics of study participants

\begin{tabular}{|c|c|c|c|c|}
\hline Characteristics & Overall $(N=378)$ & Patients $(N=177)$ & $\operatorname{MGP}(N=201)$ & $\begin{array}{l}\text { Proportion of KSA } \\
\text { population (citizens) } \\
{[23]}\end{array}$ \\
\hline \multicolumn{5}{|l|}{ Participant type } \\
\hline Patients & $177(46.8)$ & $177(100)$ & & \\
\hline Non-patients & $201(53.2)$ & & $201(100)$ & \\
\hline \multicolumn{5}{|l|}{ Sex } \\
\hline Male & $278(73.5)$ & $135(76.3)$ & $143(71.1)$ & $51.0 \%$ \\
\hline Female & $100(26.5)$ & $42(23.7)$ & $58(28.9)$ & $49.0 \%$ \\
\hline \multicolumn{5}{|l|}{ Age group, years } \\
\hline $18-25$ & $39(10.3)$ & $2(1.1)$ & $37(18.4)$ & $11.2 \%(19-24$ years $)$ \\
\hline $26-35$ & $83(22.0)$ & $8(4.5)$ & $75(37.3)$ & $19.3 \%(25-34$ years $)$ \\
\hline $36-45$ & $82(21.7)$ & $30(17.0)$ & $52(25.9)$ & $12.6 \%(35-44$ years $)$ \\
\hline $46-55$ & $66(17.5)$ & $44(24.9)$ & $22(10.9)$ & $8.2 \%$ (45-54 years) \\
\hline $56-65$ & $72(19.0)$ & $61(34.5)$ & $11(5.5)$ & $4.1 \%$ (55-64 years) \\
\hline $66-75$ & $28(7.4)$ & $25(14.2)$ & $3(1.5)$ & $2.2 \%(65-74$ years $)$ \\
\hline$\geq 76$ & $8(2.1)$ & $7(3.9)$ & $1(0.5)$ & $1.1 \%(\geq 75$ years $)$ \\
\hline \multicolumn{5}{|l|}{ Education level } \\
\hline Attended but not completed secondary school & $74(19.6)$ & $62(35.0)$ & $12(6.0)$ & $12.8 \%$ \\
\hline Apprenticeship or trade certificate/diploma & $9(2.4)$ & $5(2.8)$ & $4(2.0)$ & NA \\
\hline Secondary school diploma or equivalent & $68(18.0)$ & $32(18.1)$ & $36(17.9)$ & $34.6 \%$ \\
\hline University certificate or diploma below bachelor's & $33(8.7)$ & $16(9.0)$ & $17(8.5)$ & NA \\
\hline Bachelor's degree & $157(41.5)$ & $46(26.0)$ & $111(55.2)$ & $38.9 \%$ \\
\hline University certificate or diploma above bachelor's & $37(9.8)$ & $16(9.0)$ & $21(10.5)$ & $3.2 \%$ \\
\hline \multicolumn{5}{|l|}{ Employment status } \\
\hline At home (spouse, not working) & $39(10.3)$ & $25(14.1)$ & $14(7.0)$ & NA \\
\hline Unemployed, including non-working student & $49(13.0)$ & $9(5.1)$ & $40(19.9)$ & $12.7 \%^{\mathrm{a}}$ \\
\hline Retired & $78(20.6)$ & $63(35.6)$ & $15(7.5)$ & NA \\
\hline Employed (privately) & $36(9.5)$ & $10(5.7)$ & $26(12.9)$ & NA \\
\hline Employed (government) & $155(41.0)$ & $55(31.1)$ & $100(49.8)$ & NA \\
\hline Self-employed/business owner & $21(5.6)$ & $15(8.5)$ & $6(3.0)$ & NA \\
\hline \multicolumn{5}{|l|}{ Monthly income, SAR } \\
\hline Declined to answer & $5(1.3)$ & $3(1.7)$ & $2(1.0)$ & NA \\
\hline $0-3000$ & $27(7.1)$ & $21(11.9)$ & $6(3.0)$ & NA \\
\hline $3001-6000$ & $52(13.8)$ & $25(14.2)$ & $27(13.4)$ & NA \\
\hline $6001-12,000$ & $104(27.5)$ & $46(26.0)$ & $58(28.9)$ & NA \\
\hline $12,001-20,000$ & $85(22.5)$ & $39(22.0)$ & $46(22.9)$ & NA \\
\hline$>20,000$ & $105(27.8)$ & $43(24.3)$ & $62(30.8)$ & NA \\
\hline
\end{tabular}

Data are presented as $N(\%)$ unless otherwise indicated

Citizens citizens of KSA, KSA Kingdom of Saudi Arabia, MGP members of the general public, $N$ sample size, NA not available, SAR Saudi Riyals

${ }^{\mathrm{a} O v e r a l l ~ e m p l o y m e n t ~ r a t e ~ o f ~} 87.3 \%$

not to compare results between patients and MGP, although we present results for both, but rather to present a combined estimate.

With regards to adjusting our results over the KSA population, the sensitivity analyses projecting the WTP result over corresponding age and sex demographics of the KSA, we obtained figures very similar to our main results adjusted for outliers. However, there were differences in the results between the patients and the MGP, either for the overall analysis or in comparisons of results between various demographic subgroups. It has been suggested that preferences from the general population, rather than those from patients, should be used in cost-effectiveness analysis [18]. For the overall WTP results, the patient group reported a median of $\$$ US11,100, whereas the median for the MGP was $\$$ US42,700 for the 1-year horizon, with a significant 
Table 2 Summary results of mean utility scores

\begin{tabular}{llll}
\hline Utilities & $\begin{array}{l}\text { Overall } \\
\text { dataset } \\
(N=378)\end{array}$ & $\begin{array}{l}\text { One-way adjusted } \\
\text { dataset }(N=270)^{\mathrm{a}}\end{array}$ & $\begin{array}{l}\text { Two-way adjusted } \\
\text { dataset }(N=220)^{\mathrm{b}}\end{array}$ \\
\hline General public & 0.499 & 0.519 & 0.508 \\
Patients & 0.316 & 0.438 & 0.416 \\
Total group & 0.413 & 0.487 & 0.472 \\
\hline
\end{tabular}

$W T P$ willingness to pay

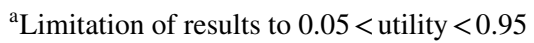

${ }^{\mathrm{b}}$ Limitation of results to $0.05<$ utility $<0.95$ and $10 \%<\mathrm{WTP}<90 \%$

difference $(p<0.001)$. For the 5 -year horizon analyses, the patient group reported a median of $\$ \mathrm{US} 10,000$, whereas the MGP reported a median of $\$$ US31,000 $(p<0.001)$. WTP results tended to increase with the reported utility measures (Fig. 3). WTP results tended to decrease with age (Fig. 4). There were some significant differences between various other subgroups, such as between "bachelor's degree" and "secondary diploma" and between "university degree above bachelor's" and "secondary diploma." However, no significant difference was found between "bachelor's degree" and "registered apprenticeship or trade certificate" (data not shown).

Furthermore, other patient-based results using a TTO survey reported in the USA were almost similar, at \$US22,700-32,200 per QALY [5]. Bobinac et al. [25] reported WTP per QALY values in the Netherlands of about $€ 13,000$ based on visual analog scale valuations and of $€ 24,500$ based on EuroQol tariffs. Cameron et al. [1] reported that most of the threshold values, in countries where they were available, fell within a range of one to three times the respective GDP per capita [1]. The present study provides WTP thresholds that are very similar to the GDP of $\$$ US20,000 in the KSA, within a range of approximately 1-1.5 times the GDP per capita [26].

Based on the results of the present study, should one be attempting to select boundaries of a range for WTP per QALY thresholds, we suggest expected ICERs $<\$$ US20,000 be considered attractive, as that is approximately the calculated median for the 5-year time horizon, whereas ratios $>\$ U S 60,000$ may be considered much less attractive, as it approximates the higher end of the reported means. Ratios falling between these amounts should be assessed
Table 3 Comparative quantiles values of WTP by type of respondent, 1-year horizon
Table 4 Comparative quantiles values of WTP by type of respondent, 5-year horizon

\begin{tabular}{lcccc}
\hline WTP for a QALY & Patient $(N=177)$ & Non-patient $(N=201)$ & Overall $(N=378)$ & Adjusted sample $^{\mathrm{a}}$ \\
\hline Mean & 323 & & 443,730 & 58,053 \\
Minimum & 945 & 640 & & \\
$10 \%$ & 4037 & 3965 & & \\
$25 \%$ & 13,128 & 42,972 & 32,000 \\
Median & 37,647 & 128,800 & 25,600 & \\
$75 \%$ & 113,664 & 452,118 & & \\
$90 \%$ & $7,680,000$ & $38,400,000$ & & \\
Maximum & & & & \\
\hline
\end{tabular}

WTP values are presented in \$US

$Q A L Y$ quality-adjusted life-year, $W T P$ willingness to pay

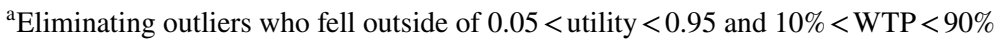

\begin{tabular}{lrrll}
\hline WTP for a QALY & Patient $(N=177)$ & Non-patient $(N=201)$ & Overall $(N=378)$ & Adjusted sample $^{\mathrm{a}}$ \\
\hline Mean & & & 257,632 & 38,642 \\
Minimum & 323 & 323 & & \\
$10 \%$ & 2049 & 2560 & & \\
$25 \%$ & 6452 & 6827 & & 22,720 \\
Median & 9950 & 31,069 & 19,200 & \\
$75 \%$ & 32,202 & 88,208 & & \\
$90 \%$ & 96,807 & 297,384 & & \\
Maximum & $7,680,000$ & $19,200,000$ & & \\
\hline
\end{tabular}

WTP values are presented in \$US

$Q A L Y$ quality-adjusted life-year, WTP willingness to pay

${ }^{a}$ Eliminating outliers who fell outside of $0.05<$ Utility $<0.95$ and $10 \%<$ WTP $<90 \%$ 


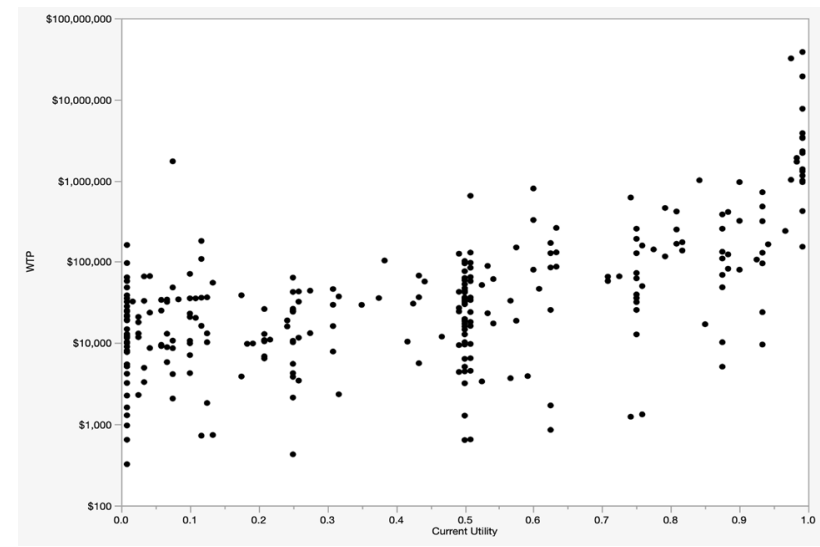

Fig. 3 Log representation of WTP per quality-adjusted life-year (1 year) by current health utility. WTP willingness to pay

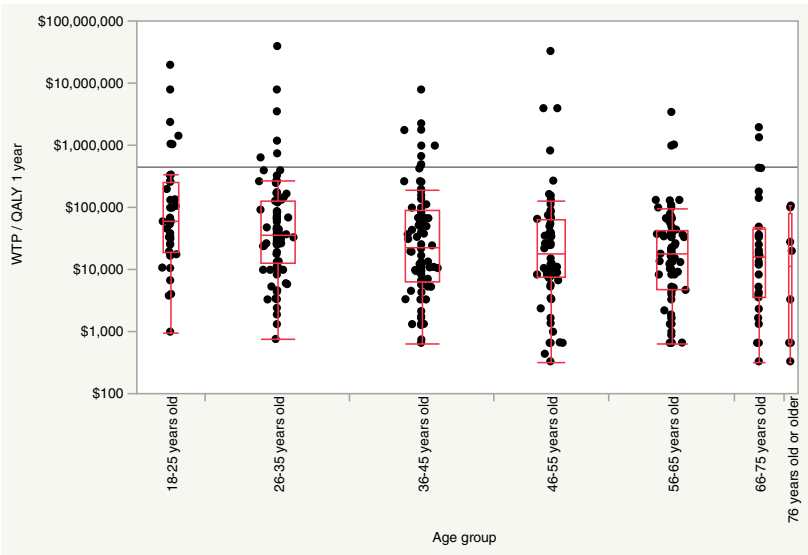

Fig. 4 One-way analysis of WTP/QALY, 1-year horizon, by age group. $Q A L Y$ quality-adjusted life-year, $W T P$ willingness to pay

individually according to overall and specific conditions and limitations.

One of the major limitations of this study, as mentioned, is the relatively small sample size when taking a countrywide perspective, although it was adequate for this type of study within a delimited segment of the cancer population in the KSA. Also, as no breakdown between family members and other MGP was reported, because it was not part of the study protocol, we could not determine differences in WTP between these two groups. Furthermore, the adjustments made by eliminating the outliers, including those reporting zero utility, further reduced the size of the sample. In addition, the present sample, based on sociodemographic characteristics of participants, especially with a skewed sex distribution, may not be representative of the KSA as a whole. Nonetheless, we believe it may be sufficiently representative, at the very least for the cancer population in the capital.
Furthermore, one limitation, which may also be a strength, is that this is the first study of its kind. With all its limitations and lack of overall population representativeness, it remains the study to which future studies will be compared.

\section{Conclusion}

This study empirically estimated WTP for QALY thresholds of \$US19,000-32,000 based on medians and is, to our knowledge, the first study to determine the WTP per QALY in the KSA. Hence, within certain limitations and under certain conditions, we consider it appropriate as a reference until further evidence is determined.

Author Contributions SB: research idea and conceptualization, development of scenarios, development of analysis plan, interpretation and discussion of results, review of manuscript. EBDeV: development of analysis plan and analyses, interpretation and discussion of results, review of manuscript. FM: discussion of analysis plan, discussion of results, review of manuscript. AA-J, AAA, AMA, and IAA: discussion of analysis plan, interpretation and discussion of results, review of manuscript. MI: research idea and conceptualization, development of WTP tool, development of analysis plan and analyses, interpretation and discussion of results, writing and review of manuscript.

\section{Compliance with Ethical Standards}

Funding This study was sponsored by the King Faisal Specialist Hospital and Research Centre, through Grants from Pfizer, Bristol-Myers Squibb, Sanofi, and Bayer. The authors retained the right to publish, regardless of results and without censorship of the manuscript by the granting parties. Results of this study do not present any known or perceived bias, as no drug or product manufactured or marketed by the granting parties were the subject of analyses.

Ethical approval This study was approved by the ethics review board of King Faisal Specialist Hospital and Research Centre, Riyadh, KSA, and was performed in accordance with the ethical standards of the Declaration of Helsinki.

Informed consent All study participants signed informed consent prior to starting the survey. Participants could withdraw from the study at any point during the survey.

Conflict of interest Drs. Bazarbashi, De Vol, Maraiki, Al-Jedai and Ali are employed by KFHSRC. Dr. Alhammad was, at the time of analysis, employed by National Guard Health Affairs, King Abdulaziz Medical City. Dr. Aljuffali is employed by King Saud University. Michael Iskedjian is the owner of PharmIdeas USA Inc., an independent research and consulting firm in the fields of health economics and outcomes research. Dr. Bazarbashi has received honoraria from, and/or has been on advisory boards for Pfizer, Bristol-Myers Squibb, Sanofi and Bayer. Michael Iskedjian has in the past performed studies for all four companies but reports no conflict at present time. None of the other co-authors report any conflict of interest.

Data Availability The dataset used for analyses is provided as supplementary material in the form of a Microsoft Excel file. 
Open Access This article is licensed under a Creative Commons Attribution-NonCommercial 4.0 International License, which permits any non-commercial use, sharing, adaptation, distribution and reproduction in any medium or format, as long as you give appropriate credit to the original author(s) and the source, provide a link to the Creative Commons licence, and indicate if changes were made. The images or other third party material in this article are included in the article's Creative Commons licence, unless indicated otherwise in a credit line to the material. If material is not included in the article's Creative Commons licence and your intended use is not permitted by statutory regulation or exceeds the permitted use, you will need to obtain permission directly from the copyright holder.To view a copy of this licence, visit $\mathrm{http} / / /$ creativecommons.org/licenses/by-nc/4.0/.

\section{References}

1. Cameron D, Ubels J, Norström F. On what basis are medical cost-effectiveness thresholds set? Clashing opinions and an absence of data: a systematic review. Glob Health Action. 2018;11(1):1447828.

2. Laupacis A, Feeny D, Detsky AS, et al. How attractive does a new technology have to be to warrant adoption and utilization? Tentative guidelines for using clinical and economic evaluations. CMAJ. 1992;146:473-81.

3. Jaswal A. Valuing health in Canada: Who, how, and how much? Canada 2020 Analytical Commentary: No. 3. Ottawa: Canada2020.ca, 2013.

4. Bridges JFP, Eberechukwu O, Mullins CD. Health rationing by proxy. Cost-effectiveness analaysis and the misuse of the $\$ 50,000$ threshold in the US. Pharmacoeconomics. 2010;28(3):175-84.

5. King JT Jr, Tsevat J, Lave JR, Roberts MS. Willingness to pay for a quality-adjusted life year: implications for societal health care resource allocation. Med Decis Mak. 2005;25:667-77.

6. Devlin N, Parkin D. Does NICE have a cost-effectiveness threshold and what other factors influence its decisions? A binary choice analysis. Health Econ. 2004;13(5):437-52.

7. Baker R, Chilton S, Donaldson C, Jones-Lee M, Lancsar E, Mason $\mathrm{H}$, Metcalf $\mathrm{H}$, Pennington M, Wildman J. Searchers vs surveyors in estimating the monetary value of a QALY: resolving a nasty dilemma for NICE. Health Econ Policy Law. 2011;6(4):435-47.

8. Giardina S, Pane B, Spinella G, Cafueri G, Corbo M, Brasseur P, Orengo G, Palombo D. An economic evaluation of an abdominal aortic aneurysm screening program in Italy. J Vasc Surg. 2011;54(4):938-46.

9. Knight C, Mauskopf J, Ekelund M, Singh A, Yang S, Boggs R. Cost-effectiveness of treatment with etanercept for psoriasis in Sweden. Eur J Health Econ. 2012;13(2):145-56.

10. Uegaki K, Bakker I, De Ruijne M, Van der Beek A, Terluin B, van Marwijk H, Heymans M, Stalman W, van Mechelen W. Cost-effectiveness of a minimal intervention for stress-related sick leave in general practice: results of an economic evaluation alongside a pragmatic randomised control trial. J Affect Disord. 2010;120(1-3):177-87.
11. Mauskopf J, Chirila C, Masaquel C, Boye KS, Bowman L, Birt $\mathrm{J}$, Grainger D. Relationship between financial impact and coverage of drugs in Australia. Int J Technol Assess Health Care. 2013;29:92-100.

12. Grosse SD. Assessing cost-effectiveness in healthcare: history of the \$50,000 per QALY threshold. Expert Rev Pharmacoecon Outcomes Res. 2008;8(2):165-78.

13. Rudmik L, Drummond M. Health economic evaluation: important principles and methodology. Laryngoscope. 2013;123(6):1341-7.

14. Claxton K, Martin S, Soares M, Rice N, Spackman E, Hinde S, Devlin N, Smith PC, Sculpher M. Methods for he estimation of the National Institute for Health and Care Excellence cost-effectiveness thresholds. Health Technol Assess. 2015;19(14):1.

15. Soares Santos A, Guerra-Junior AA, Godman B, Morton A, Mariano RC. Cost-effectiveness thresholds: methods for setting and examples from around the world. Expert Rev Pharmacoecono Outcomes Res. 2018;18(3):277-88.

16. https://www.calculator.net/sample-size-calculator.html. Accessed 17 May 2016.

17. https://www.raosoft.com/samplesize.html. Accessed 17 May 2016.

18. Gold MR, Patrick DL, Torrance GW, et al. Identifying and valuing outcomes. In: Gold MR, Siegel JE, Russell LB, Weinstein MC, editors. Cost-effectiveness in health. New York: Oxford University Press; 1996. p. 82-123.

19. Froberg DG, Kane RL. Methodology for measuring healthstate preferences-II: scaling methods. J Clin Epidemiol. 1989;42(5):459-71.

20. Iskedjian M, Tinmouth AT, Arnold DM, et al. Elicitation of utility scores in Canada for immune thrombocytopenia treated with romiplostim or watch and rescue. J Health Econ. 2012;15(2):313-31.

21. Frew EJ, Wolstenholme JL, Whynes DK. Comparing willingnessto-pay: bidding game format versus open-ended and payment scale formats. Health Policy. 2004;68(3):289-98.

22. Iskedjian M, Desjardins O, Piwko C, Bereza B, Jaszewski B, Einarson TR. Willingness to pay for a treatment for pain in multiple sclerosis. Pharmacoeconomics. 2009;27(2):149-58.

23. Iskedjian M, Iyer S, Librach SL, Wang M, Farah B, Berbari J. Methylnatrexone in the treatment of opioid-induced constipation in cancer patients receiving palliative care: willingness-to-pay and cost-benefit analysis. J Pain Symptom Manag. 2011;41(1):104-15.

24. Kingdom of Saudi Arabia, General Authority of Statistics. Population by Gender, Age Groups and Nationality. Riyadh: 2019. https ://www.stats.gov.sa/en. Accessed 27 Mar 2020.

25. Bobinac A, van Exel NJA, Rutten FFH, Brouwer WBF. Willingness to pay for a quality-adjusted life-year: the individual perspective. Value Health. 2010;3(8):1046-55.

26. World Bank. GDP per capita. World Bank national accounts data, and OECD National Accounts data files. https://data.worldbank. org/indicator/ny.gdp.pcap.cd?locations $=$ sa. Accessed 15 Feb 2019. 